\title{
Working memory capacity and the retention of L2 vocabulary
}

\section{Mallce Borges Mota Fortkamp}

Professora do Programa de Pós-Graduaçāo em Letras/Inglês e Literatura Correspondente da Universidade Federal de Santa Catarina. Tem experiência na área de Lingüistica, com ênfase em Lingüistica Aplicada e Psicologia Cognitiva. Atualmente está em estágio pós-doutoral no Brain \& Language Lab, Departamento de Neurociência, Georgetown Medical Center, Georgetown University.

Abstract: this study examines the relationship between working memory capacity and vocabulary retention in English as a L2. The study was conducted with seventeen advanced speakers of English. Statistical analyses revealed that working memory capacity correlates significantly with L2 vocabulary retention. This correlation was interpreted as an indication that higher spans are better able to comprehend and produce new vocabulary items in a L2 than lower spans.

\section{Daniela Malheiros Mendonça}

Mestre em Letras (Inglês e Literatura Correspondente) pela Universidade Federal de Santa Catarina (2003). Atualmente é professora da Universidade de Passo Fundo (UPF Idiomas), atuando principalmente nos seguintes temas: aquisiçāo de língua estrangeira, leitura, memória operacional, estratégias de aprendizado e lingüistica aplicada.

\section{Resumo: este estudo investiga a relaçāo entrea capacidade damemória de trabalho ea retençäo de vocabulário em Inglês como L2. O estudo foi conduzido comidezessete falantes de inglês de nivel avançado. Resultados das análises estatisticas demonstraram que a capacidade da memónia de trabalho se correlaciona de modo significativo com a retençāo de vocabulário na L2. Essa correlaçāo foi interpretada como uma indicação de que individuos com maior capacidade de memória de trabalho são mais eficazes em compreender e produzir novos itens lexicais na L2 do que indivíduos com menor capadidade.}

\footnotetext{
Palavras-chave: capacidade de memória de trabalho; retenção de vocabulário em L2; diferenças individuais

Keywords: working memory capacity; L2 vocabulary retention; individual differences 


\section{Introduction}

Research on L2 vocabulary acquisition ' has been developed mainly in terms of vocabulary size, receptive and productive vocabulary, the mother tongue influence on the learning of L2, L2 vocabulary teaching, vocabulary testing, and strategies to learn vocabulary (READ, 2000; SCHMITT \& MCCARTHY, 1997). Nevertheless, to date, no research has been carried out on the relationship between individual differences in working memory capacity and L2 vocabulary retention.

In contemporary cognitive psychology, working memory is considered to be at the heart of human cognition (ASHCRAFT, 1994) and is conceptualized as an arena where human cognitive processes occur (KANE, CONWAY, HAMBRICK \& ENGLE, 2007; JUST \& CARPENTER, 1992). As a cognitive system, working memory is in charge of manipulating information and storing it for a limited period of time during the performance of demanding cognitive tasks (KANE, POOLE, TUHOLSKI, \& ENGLE, 2006).

A massive body of research carried out over the last 30 years demonstrates that individuals vary in their working memory capacity and that this variation is related to the performance of complex cognitive tasks such as reading, speaking, reasoning, and learning (see, for instance, UNSWORTH \& ENGLE, 2007). The interpretation of this relationship has been generally presented as an indication that individuals with a larger working memory capacity are better able to deal with the processing and storage demands of the task, which results in better performance.

The present study sets out to investigate the relationship between individual differences in working memory capacity (WMC) and the retention of L2 vocabulary. More specifically, the study aims at examining whether individuals with a larger working memory capacity are better able to retain L2 lexical items than those individuals with a smaller capacity and whether there is a difference between the strategies higher and lower working memory capacity individuals use to retain
1 The terms acquisition, learning, and retention are used interchangeably in this study. 
L.2 vocabulary. The present study investigates the following hypotheses:

(1) Individuals with larger working memory capacity are better able to transfer recently learned items to long-term memory than individuals with smaller working memory capacity, and

(2) The vocabulary learning strategies used by individuals with larger working memory capacity differ in number and type from those used by individuals with smaller working memory capacity.

In what follows, we briefly present the theoretical background to the study, the method, the results, and our conclusions on what these results might show concerning the retention of L2 vocabulary.

\section{Theoretical background}

As Baddeley (1992) has wisely pointed out, research on working memory research has been carried out under two main perspectives. The first, named by Baddeley (1992) the dual-task and neuropsychological perspective, focuses on the analysis of the architecture of the working memory system (BADDELEY \& HITCH, 1974) and emphasizes the slave subsystems. Its methodology includes the study of neuropsychological evidence and the application of dual tasks.

The second perspective, the psychometric correlational, focuses on the correlation between individual differences in working memory capacity and performance of cognitive abilities (DANEMAN \& CARPENTER, 1980, 1983). Researchers in this perspective believe that working memory capacity is a good predictor of individual differences and that individuals with larger working memory capacity perform better in complex cognitive tasks than those individuals with smaller working memory capacity. In this view, the two functions of working memory - storage and processing of information (BADDELEY, 1992; 
DANEMAN, 1991) - compete while high cognitive skills are performed (DANEMAN \& CARPENTER, 1980, 1983). The methodology used in this perspective includes the design of laboratory tasks that require the simultaneous processing and storage of information.

Since the psychometric correlational perspective emphasizes that individual differences in working memory capacity are good predictors of performance, many studies on individual differences have been developed in the fields of reasoning and reading comprehension in first language (BADDELEY, 1992). The most classic and relevant study within the psychometric correlational approach was conducted by Daneman and Carpenter (1980) in the language domain. These researchers investigated the correlation between working memory capacity and reading and proposed the reading span task, a complex measure of working memory span for reading comprehension. In subsequent work, Daneman and Green (1986), proposed the speaking span test, which assesses working memory capacity during sentence production.

Originally devised to assess performance on L1 tasks, the span tests have also been adapted to assess performance on L2 tasks. Thus, for instance, in the area of reading comprehension, Harrington (1991 1992) found a strong correlation between working memory capacity and measures of L2 lexicon, grammar, and L2 reading. Berquist (1998) investigated the relationship between L.1 and I.2 working memory reading, and L2 proficiency. Significant correlations were found among L2 word and reading spans and L.2 proficiency. The most significant result was the strong correlation between an L.2 cloze test and L.2 proficiency. Berquist (1998) concludes that these results show that L.2 working memory is a good predictor of L2 proficiency. In Brazil, Torres (1998) investigated the relationship among previous knowledge, L2 working memory capacity, and $L 2$ reading comprehension. Her results showed that due to the heavy burden of the information processing in $\mathrm{L} 2$, the participants' reading span in the L2 was smaller than in the L1. Participants' scores 
on the span and reading tests were higher when domain knowledge was high. Torres claims that processing difficulties in L2 can be, to a certain point, compensated by knowledge activation. Torres also sustains that the processing efficiency of the participants has an effect on their working memory capacity and on their comprehension and retrieval abilities.

In the area of speech production, Fortkamp (1999) investigated the relationship between working memory capacity, L2 speech rate, and L2 articulation and found that individuals with higher spans are also more fluent when speaking the L2. In a follow-up study, Fortkamp (2003) set out to investigate the relationship among working memory capacity, fluency, accuracy, complexity, and lexical density in L2 speaking. The results demonstrated that higher span speakers are also more fluent and accurate in their oral performance, which tends to be also more grammatically complex. However, the speech of these higher span individuals tends to be less lexically dense. To explain these results, Fortkamp (2003) takes an attentionview of working memory capacity and claims that higher span individuals have more attentional resources available to deal with the demands of L2 speaking.

The relationship between working memory capacity and L2 skills has been explored mainly from a performance-based perspective and relatively few studies have devoted attention to the role of this cognitive system in the acquisition of new information. The present study is, thus, an initiative towards this direction.

\section{Method}

\section{Participants}

Seventeen students of the Graduate Program in English Language and Literature at the Federal University of Santa Catarina (UFSC) were selected, on a voluntary basis, to participate in the study. From these, 12 were female and 5 were male. There were sixteen native speakers of Brazilian Portuguese and one Mexican native 
speaker of Spanish. All seventeen participants had a high level of competence in English and were able to listen, read, write and speak fluently in the language. Fourteen participants were in the first semester of their Master of Arts (M.A.) course, and three participants were in the third semester of their M.A. course, in the thesis phase.

\section{Materials}

In order to address the hypotheses of the present study, an experiment consisting of six tasks was carried out. From the six tasks, five aimed at assessing vocabulary retention and one aimed at assessing working memory capacity.

The first task applied was devised to determine the words to be selected for this study. The second task was the Speaking Span Test (adapted from DANEMAN, 1991), aimed at assessing participants' working memory capacity in oral production tasks. The third one was the teaching of twenty unknown words in English. The fourth task was the production of a narrative (Productive Test), whose objective was to verify participants' learning of the words taught in the third task. The fifth task was a Receptive Test whose goal was to assess learning of the words taught. Finally, an interview with the participants was carried out, aimed at identifying which strategies they apply to retain and use vocabulary, in general, and to retain the words taught in task 3 of this experiment, in particular.

\section{The first task - the selection of words}

For the first task in this study, a questionnaire with sixty supposedly unknown words in English was applied to the participants in order to determine which words they were not familiar with. Participants had to complete the task providing either the definition or/and the translation of the word in Portuguese. Through the analysis of the results of this first task, the researchers could identify twenty unknown words that were not translated or defined by any of the participants. The unknown words - seven nouns, three adjectives, ten verbs - were the following: 
abbot (noun), chasm (noun), composure (noun), contemptuous (adjective), mien (noun), nonchalance (noun), sweeping (adjective), thrust (noun), to amass (verb), to deploy (verb), to dispel (verb), to engender (verb), to espouse (verb), to ingratiate (verb), to preclude (verb), to proffer (verb), to proscribe (verb), to sidetrack (verb), trade-off (noun), ubiquitous (adjective). These words were thus selected to be taught in the third task of the experiment.

\section{The second task - the speaking span test}

The second task of the data collection and the only memory assessment task, was the Speaking Span Test (SST), adapted from Daneman (1991) and applied individually to each one of the seventeen participants. The SST comprised forty words organized in sets of two, three, four, five, and six words. The participants were first instructed on how to perform the task and, upon their agreement, were then presented with the sets of words. They were asked to recall each word in the sets and to produce, at the end of the presentation of a set, one sentence for each word presented, in their form and order of presentation. Words were presented individually, for one second, on a computer screen and a beep would signal the end of a set. There were two sets of two, three, four, five, and six words. The interval between the words presented within a set was ten milliseconds. The following word of the set only appeared when the previous one of the same set was removed. A participants span was defined as the total number of correct sentences produced.

\section{The third task - teaching vocabulary}

The third task consisted of the teaching the twenty unknown words chosen from the first task, following Nation (2001). The words selected were taught in an 1hour class. Three different activities were prepared for the class. The first consisted of the presentation of the twenty unknown words within a text, as suggested by Elley (1989) and Brett, Rothlein and Hurley (1996). In 
the second activity participants were asked to match these new words with their appropriate definitions. In the third task participants were given cards with the words written on them and were asked to produce sentences orally with the words on the cards. Due to the difficulty of gathering participants on the very same day, this class was given to 3 different groups of participants, organized according to their time constraints. It is important to state, though, that the same procedures were followed in all three meetings.

The fourth task - the production of a narrative (Productive test)

In the fourth task, participants' vocabulary retention was assessed by means of a Productive Test (NATION, 1983, 1990). One week after the third task, participants were individually required to construct a narrative using the words taught in class the week before. This task was tape-recorded and its objective was to assess participants' vocabulary retention in an oral production task. Participants were presented with a poster whose pictures depicted most of the words taught in class. Participants were given two minutes to plan the narrative (NATION, 2001) mentally. They were not allowed to write or any material while planning their narratives. They were told that they did not need to use all the pictures to construct the narrative (NATION, 2001), or to follow the order of the pictures. They were also told they would have five minutes to narrate. In case they decided to stop the narrative before time was over, they were allowed to. The researchers indicated to the participants when they had only one minute left to finish their narration. Participants' narratives were transcribed and the number of words recalled counted, the maximum score being 20 words.

\section{The fifth task - the receptive test}

In the fifth task, a receptive test was devised in order to determine participants' vocabulary retention in recognition tasks. In the production of a narrative, 
participants had to recall the L2 words and produce them in a sentence, whereas in the Receptive Test, participants had to recognize the $\mathrm{L} 2$ words and translate them into their first language. In this test, participants had to provide either the definition and/or the translation of the twenty words taught. Again, the maximum score was 20.

\section{The sixth task - the Interview}

An interview with each participant was performed right after the production of the narrative. Participants were asked to report the strategies they apply to learn and recall vocabulary in general and the strategies they used to learn and recall the vocabulary items taught in the class given by the researchers.

\section{Results}

Results from Pearson Product Moment Coefficient of Correlation showed correlations at the .05 level (2-tailed) between the Speaking Span Test scores and the productive test scores $(r=.586)$. These results might indicate that the participants who presented higher performance in the working memory capacity test were also more prone to recalling and producing vocabulary items in the productive task, the narrative that participants were asked to produce orally. These results might also indicate that the participants who obtained lower scores in the working memory capacity test were less prone to recalling and producing vocabulary items in the productive task.

Results from Pearson Product Moment Coefficient of Correlation also showed a 2-tailed positive correlation between the SST and the receptive test scores $(r=.419)$. These results might indicate that higher spans, as measured by the Speaking Span Test, are more prone to recognizing recently learned L2 vocabulary than lower spans. These results might also indicate that the Speaking Span Test, originally devised to tax working memory capacity in language production, was also able to capture processes 
involved in word recognition. In fact, Melka (1997) has stated that vocabulary productive processes are difficult to be distinguished from receptive processes in relation to conceptualization and assessment. Thus, it could be that upon translating and giving definition to the words in the receptive test, participants activated productive processes.

Hypothesis 1 predicted that individuals with larger working memory capacity would also be more able to retain new vocabulary items, as measured by the productive and the receptive tests. The results reported above lend support to hypothesis 1. Individuals who presented higher scores in the working memory span measure were also more prone to retaining more vocabulary items. In turn, individuals who presented lower scores in the working memory span measure tended to retain fewer vocabulary items.

Concerning Hypothesis 2 of this study, we conducted an interview with each participant in order to examine whether the vocabulary learning strategies applied by individuals with larger working memory capacity differed in quantity and type from those applied by individuals with smaller working memory capacity. In order to examine their strategies in detail, participants were divided into two groups - one consisting of higher spans (those who scored 25 and above on the SST) and one consisting of lower spans (those scored 15 and below on the SST).

The following are strategies that both higher and lower span participants reported they use: (a) writing down the new L2 word, (b) reading the text several times, (c) reading the exercises several times, (d) imagining either the new L2 word or the context, (e) making cards, (f) producing sentences and using the L2 new word in a context, and ( $\mathrm{g}$ ) looking up the new L2 word in a dictionary (SCHMITT \& MCCARTHY, 1997).

A number of researchers have documented the reported use of these strategies by L2 learners. Wahring and Nation (1997), for instance, state that writing down new L2 words in a notebook in order to register it and to 
gather the necessary information of its features is one of the vocabulary learning strategies used by L2 learners. Nation (2001) puts forward that repetition is crucial for learning new words due to the fact that an individual may not learn the great array of information a word has in just one meeting. Nation (2001, p. 66) claims that "first language translations are probably the simplest kind of definition in that they are short and draw directly on familiar experience" (p. 66). Thus, Nation (2001) emphasizes that the use of cards which have the word translation in the individuals' mother tongue contribute to their faster vocabulary learning. Nation (2001) mentions Judd's study (1978), which shows that words presented out of context are not usually recalled. Nation (2001) points out that consulting a dictionary demands time but that dictionaries are a great help for learning as well as for comprehension, mainly in the case of those learners who are not very skilled in guessing from context.

Despite having some strategies in common, higher and lower span participants also differ in the quantity and type of the strategies they use to retain new L2 vocabulary. The strategies only higher span individuals indicated they use were: (a) making several kinds of associations, (b) working out the spelling of the new L2 word, (c) drawing or making pictures of the target L2 word, (d) memorizing (COHEN \& APHEK, 1981) the sentences which contained the new L2 word as well as memorizing the new L2 word, (e) attempting to remember the target word, and (f) retelling the story. Again, these strategies have been well-documented in the literature. Oxford (1990) states that associations help to reinforce comprehension and make information easier to be recalled. For instance, participant 1 - a higher span - reports that

"...I try to make up sentences and I associate these with very strange things in order to try to kind of shock me and then, I will remember the word. For example, for me, the words in the story, when I was studying them this afternoon, and then I was 
imagining the whole scene ... It is not usual to talk about this all the time and so, if you visualize what's going on and associate the words with images, then, I guess, it's better for me to learn them. I'll remember them later on."

The analysis of the interview also revealed that the higher spans used imagery and visualization to recall word meanings in both the productive and receptive tests. These results are supported by the existing literature on vocabulary acquisition that claims that individuals make use of visual memory to acquire vocabulary (READ, 2000; NATION, 2001). For instance, Nagy (1997) stresses that there is little possibility that one will get vocabulary meaning in just one encounter. Nation (1990) claims that several studies show that one has to come across a word from 5 to 16 times in order for her/him to effectively acquire it. Sökmen (1997) states that when individuals run into a target word in several contexts and activities, they will consequently obtain a more precise understanding of the meaning and use of this word. Thus, the more the target word is encountered and practiced, the more chances it has to be acquired.

The strategies lower span individuals reported they use to learn new L2 vocabulary were: (a) visualizing the written word, (b) verifying the word form and attempting to recall its meaning and vice-versa, and (c) remembering the context.

As can be seen, lower spans seem to use fewer and mostly receptive learning strategies, that is, strategies that do not involve word production. These strategies might prevent learners from actually knowing whether they are able to recall or produce the target word properly, in terms of semantic meaning, spelling, pronunciation, and context of use. For instance, participant 8 - a lower span - explains the use of his/her strategy:

"Ah well, I read the text, so I understood the context within the text and then I remembered, well not all of them, how those words were used in the text". 
These results might indicate that lower spans have a smaller repertoire of strategies than higher spans and that lower spans tend to use the same strategies for learning any kind of word, indistinctively from its class.

\section{Strategies to recall the L2 words taught}

The strategies that only higher spans made use of to recall the twenty words taught: (a) creating sentences, (b) searching for the word category, (c) attempting to recall the target word meaning, (d) paying attention to where to use the new word, and (e) memorizing the target word.

Some of the strategies applied by higher spans to recall the twenty words receive support from researchers in the vocabulary learning field. Concerning searching the word category, Aitchison (1996) explains the process by asserting that when an individual is aware of the word category, s/he may search the appropriate category 'file' as if $s$ he were looking for a book in a library. For instance, participant 6 - a higher span - reports using the alphabetical order to recall vocabulary items:

"To remember them, ah (pause), what I use right now, for this type of words, I rarely use in my language, in my day to day language, I have a list in my head, especially, I think like in alphabetical order, so I try to I try to, you know, categorize them, I guess, some ah like orders like ah ah, see?"

The strategies used by lower span individuals to recall the 20 new L2 words taught were: (a) practicing the new word, (b) reading the context, (c) looking up the word meaning in a dictionary, (d) finding an equivalent L1 word, (e) recalling the sentence produced, and ( $f$ ) remembering the association.

A number of researchers have mentioned, in their studies, the strategies reported by lower spans. Nation (2001) suggests that for individuals to enhance vocabulary learning, they should practice the new words by trying to use them. Hatch and Brown (1995) claim that practicing 
the new word is an uneffective strategy if the individual's goal is receptive knowledge, that is, just comprehend word meaning. Nation (1982) states that encountering a word that can be easily translated to the learner's mother tongue (L1) facilitates word retention.

As can be seen in the results presented above, lower spans tend to use receptive learning strategies to retain L2 vocabulary. Some lower spans reported that they read the new word or the sentence where the word is inserted several times, others make an effort to recall the sentence produced with the new L2 word or to recall the new word by searching a similar word in their mother tongue, in this case, Portuguese. Finally, there are also those lower spans that stated they rely on remembering the word association - for instance, they attempt to recall words that start with the same first letter, which helps them to recall both the word itself and its meaning.

Summarizing, the results of the interview show that there seems to be a difference between higher and lower spans as regards the quantity and type of strategies they use to retain new L2 vocabulary. Hypothesis 2 is, therefore, supported. The results reveal that higher spans tend to use productive learning strategies to retain L2 vocabulary items - that is, higher spans attempt to use the target word, either writing it or producing it orally, in several types of tasks. Lower spans, on the other hand, tend to apply receptive learning strategies to retain L2 words, that is, lower spans are more prone to reading or listening to the target word. Results also reveal that higher spans might display a greater repertoire of strategies to manipulate the words to the extent of being able to use them. Lower spans, on the other hand, seem to use fewer strategies, and they tend to use the same strategies, regardless of the word class, to learn new L2 vocabulary items. All in all, the results of the present study seem to show that working memory capacity is involved in the retention of L2 vocabulary. 


\section{Final remarks}

The main objective of the present study was to investigate the relationship between working memory capacity and L2 vocabulary retention. The results revealed differences in the performance of higher spans and lower spans when transferring L2 vocabulary items to long-term memory.

In this study we have shown that the manner that higher spans used vocabulary learning strategies led them to memorize and produce more L2 words. The reason why higher spans are more prone to using more and various strategies to retain new vocabulary is not clear, but this general finding is in line with research that shows that successful learners employ a greater number of strategies than less successful learners (see, for instance, COHEN, 1998). Further research should scrutinize the relationship between working memory capacity and the learning of new L2 words so that a better understanding of the role this important cognitive system plays in the development of L2 skills can be gained. 


\section{References}

AITCHISON, J. Taming the wilderness: Words in the mental lexicon. In G. ANDERMAN \& M. ROGERS (Eds.). Words, words, words. Clevedon: Multilingual Matters, 1996. p. 15-26.

ASHCRAFT, M. H. Human memory and cognition. New York: Harper Collins, 1994.

BADDELEY, A. D. Working memory. Science, 255, 556-559. 1992.

BADDELEY, A. D., \& HITCH, G. Working memory. In G.A. BOWER (Ed.). The psychology of learning and motivation: advances in research and theory. New YorkÇ. Academic Press, 1974. p. 47-90.

BERQUIST, B. Individual differences in working memory span and L2 proficiency: capacity or processing efficiency? Paper presented at the American Association for Applied Linguistics 1998 Annual Conference, Seattle, WA, 1998.

BRETT, A., ROTHLEIN, L., \& HURLEY, M. Vocabulary acquisition from listening to stories and explanations of target words. The Elementary School Journal, 96, 415-422. 1996.

COHEN, A. D., \& APHEK, E. Easifying second language learning. Studies in Second Language Acquisition, 3, 221-236. 1981.

DANEMAN, M. Working memory as a predictor of verbal fluency. Journal of Psycholinguistic Research, 20, 445-464. 1991.

DANEMAN, M., \& CARPENTER, P. Individual differences in working memory and reading. Journal of Verbal Learning and Verbal Behavior, 19, 450-466.1980.

DANEMAN, M., \& CARPENTER, P. Individual differences in integrating information between and within sentences. Journal of Experimental Psychology: Learning, Memory and Cognition, 9, 561-584. 1983.

DANEMAN, M., \& GREEN, I. Individual differences in comprehending and producing words in context. Journal of Memory and Language, 25, 1-18. 1986. 
ELLEY, W. B. Vocabulary acquisition from listening to stories. Reading Research Quarterly, 24, 174-187.1989.

FORTKAMP, M. B. M. Working memory capacity and fluency, accuracy, complexity, and lexical density in L2 speech production. Fragmentos, 24, 69-104. 2003.

FORTKAMP, M.B.M. Working memory capacity and aspects of L2 speech production. Communication \& Cognition, 32, 259-296.1999.

HARRINGTON, M. Individual differences in L2 reading: Processing capacity versus linguistic knowledge. Paper presented at the Annual Meeting of the American Association of Applied Linguistics. New York, NY. 1991.

HARRINGTON, M. Working memory capacity as a constraint on L2 development. In R.J. HARRIS (Ed.). Cognitive processing in bilinguals. Amsterdam: Elsevier, 1992. p. 123-135.

HATCH, E., \& BROWN, C. Vocabulary, semantics, and language education. Cambridge: Cambridge University Press, 1995.

JUST, M. A., \& CARPENTER, P. A. A capacity theory of comprehension: Individual differences in working memory. Psychological Review, 99,122-149. 1992.

KANE, M.J., CONWAY, A.R.A., HAMBRICK, D.Z., AND ENGLE, R.W. Variation in working memory capacity as variation in executive attention and control. In: A.R.A. CONWAY, C. JARROLD, M.J. KANE, A. MIYAKE, AND J.N. TOUSE (Eds.). Variation in working memory. New York: Oxford University Press, 2007.p. 21-48.

KANE, M.J., POOLE, B.J., TUHOLSKI, S.W., AND ENGLE, R. W. Working memory capacity and the top-down of visual search: exploring the boundaries of executive attention. Journal of Experimental Psychology: Learning, Memory and Cognition, 749-777. 2006.

MELKA, F. Receptive vs. productive aspects of vocabulary. In N. SCHMITT \& M. MCCARTHY (Eds.). Vocabulary: Description, acquisition and pedagogy. Cambridge: Cambridge University Press, 1997.p. 84-102. 
NAGY, W. E. (1997). On the role of context in first- and secondlanguage learning, In N. SCHMITT \& M. MCCARTHY (Eds.). Vocabulary:Description, acquisition, and pedagogy. Cambridge: Cambridge University Press, 1997. p. 64-83.

NATION, I. S. P. Beginning to learn foreign language vocabulary: A review of the research. RELC Journal, 13 (1), 1436. 1982.

NATION, I. S. P. Teaching and learning vocabulary. English Language Institute: University of Wellington. 1983.

NATION, I. S. P. Learning and teaching vocabulary. New York: Newbury House, 1990.

NATION, P. Learning vocabulary in another language. Cambridge: Cambridge University Press, 2001.

OXFORD, R. Language learning strategies: What every teacher should know. New York: Newbury House/Harper and Row, 1990.

READ, J. Assessing vocabulary. Cambridge: Cambridge University Press, 2000.

SCHMI'I"T, N., \& MCCARTHY, M. (Eds.). Vocabulary: Description, acquisition and pedagogy. Cambridge: Cambridge University Press, 1997.

SÖKMEN, A. J. Current trends in teaching second language vocabulary. In N. SCHMITT \& M. MCCARTHY (Eds.). Vocabulary: Description, acquisition and pedagogy. Cambridge: Cambridge University Press, 1997. p. 237-257.

TORRES, A. C. G. Prior Knowledge, L2 working memory capacity, and $L 2$ reading comprehension: How do they relate? Dissertação de Mestrado. Florianópolis: Universidade Federal de Santa Catarina. 1998.

UNSWORTH, N. \& ENGLE, R.W. The nature of individual differences in working memory capacity: active maintenance in primary memory and controlled search from secondary memory. Psychological Review, 114, 104-132. 2007.

WARING, R., \& NATION, P. Vocabulary size, text coverage and word lists. In N. SCHMITT \& M. MCCARTHY (Eds.). Vocabulary: Description, acquisition and pedagogy. Cambridge: Cambridge University Press, 1997. p. 6-19. 